\title{
Structure and tribological property of B2-based approximants
}

\author{
CHUANG DONG ${ }^{1,2, *}$, LI-MING ZHANG ${ }^{2,4}$, QING-GANG ZHOU ${ }^{2}$, HUI-CHEN ZHANG ${ }^{3}$, \\ JEAN-MARIE DUBOIS ${ }^{4}$, QIU-HUA ZHANG ${ }^{2}$, YAO-CHUN FU ${ }^{2}$, FEI-ZHOU HE ${ }^{2}$ and FEI GE \\ ${ }^{1}$ State Key Lab. for Materials Modification by Laser, Ion and Electron Beams, Dalian University of Technology, \\ Dalian 116024 , China \\ ${ }^{2}$ Department of Materials Engineering, Dalian University of Technology, Dalian 116024, China \\ ${ }^{3}$ Institute of Materials and Technology, Dalian Maritime University, Dalian 116024, China \\ ${ }^{4}$ LSG2M, Centre D’Ingénierie des Matériaux, Parc de Saurupt, Nancy 54042, France
}

\begin{abstract}
The present paper is concerned with a special group of approximants with B2 superstructures. In the first part, recent work on structural features of the $B 2$ superstructure approximants is summarized. Experimental results obtained in $\mathrm{Al}-\mathrm{Cu}-\mathrm{Mn}$ and $\mathrm{Al}-\mathrm{Cu}$ systems are presented, where a series of $\mathrm{B2}-\mathrm{based}$ approximants are observed. These phases all have similar valence electron concentrations, in full support of the e/a-constant definition of approximants. Special emphasis is laid on the chemical twinning modes of the $\mathrm{B} 2$ basic structure in relation to the $\mathrm{Al}-\mathrm{Cu}$ approximants. It is revealed that the $\mathrm{B} 2$ twinning mode responsible for the formation of local pentagonal atomic arrangements is of $180 \%[111]$ type. This is also the origin of 5 -fold twinning of the $\mathbf{B 2}$ phase on quasicrystal surfaces. Crystallographic features of phases $B 2, \tau 2, \tau 3, \gamma$, and other newly discovered phases are also discussed. In all these phases, local pentagonal configurations are revealed.

In the second part, dry tribological properties of some AlCuFe samples containing the B2-type phases are presented. The results indicated that the $\mathrm{B} 2$ phase having their valence ratio near that of the quasicrystal possesses low friction coefficient under various loads, comparable with the annealed quasicrystalline ingot. Such a result indicates that the B2-type phase with $e / a$ near that of quasicrystal is indeed an approximant, which is in full support of the valence electron criterion for approximants.
\end{abstract}

Keywords. Quasicrystals; approximants; B2; crystal structures; tribology.

\section{Introduction}

The $\mathrm{B} 2(\mathrm{CsCl})$ superstructure is a common structure type in intermetallics. Its unit cell contains two different atoms located respectively on the vertex and the centre of a cube. Its lattice parameter is $0.29 \sim 0.31 \mathrm{~nm}$. It is one of the basic simple structures that can transform into more complex structures via twinning at the atomic level, termed chemical twinning (Andersson and Hyde 1974).

The B2-type phase is often present together with quasicrystals and has fixed coherent orientation relationship with the latter. There are many examples. A thin layer of B2 structure has been observed on quasicrystal and approximant samples, the formation of which is induced by ion-milling (Dong et al 1992; Zhang et al 1993). Direct phase transition between $B 2$ and icosahedral phase is possible in thin film quasicrystals (Chien and $\mathrm{Lu} \mathrm{1992)}$ and on the surface of quasicrystals (Beeli and Horiuchi 1994; Jenks et al 1997).

There are also many B2 superstructures observed in coexistence with quasicrystals (Dubois 1993). The most

*Author for correspondence frequently encountered are $\mathrm{B} 2, \tau 2$ (FCC, $\mathrm{CaF}_{2}$-structure), $\tau 3$ (hexagonal, $\mathrm{Al}_{3} \mathrm{Ni}_{2}$-type) and $\gamma$-brass (simple cubic, $\mathrm{Al}_{4} \mathrm{Cu}_{9}$-type). All these phases have coherent orientation relationships with quasicrystals, both icosahedral and decagonal.

All the experimental evidence indicates that these phases should have special structural correlation with quasicrystals. However, this question has largely been ignored because their diffraction features are quite different from those of quasicrystals, unlike many known approximants such as $\mathrm{Al}_{13} \mathrm{Fe}_{4}$ and $\mathrm{Al}_{3} \mathrm{Mn}$ showing pseudo symmetries by intense peaks. They were considered as approximants only recently after the discovery of the so-called $e / a$-constant line in ternary phase diagrammes. From the fact that quasicrystals and their approximants all lie near one or two straight lines with constant $e / a$ ratios, we proposed a new concept of approximants based upon valence electron concentration criterion (Dong 1995a). Such a definition reflects electronic structural correspondence between quasicrystal and approximants and widens significantly the scope of approximants. For example, there are at least three $e / a$-constant phases in the $\mathrm{Al}-\mathrm{Cu}-\mathrm{Fe}$ system, namely monoclinic $\lambda-\mathrm{Al}_{13} \mathrm{Fe}_{4}$, icosahedral $i$ - $\mathrm{Al}_{62.3} \mathrm{Cu}_{24.9} \mathrm{Fe}_{12.8}$ quasicrystal, and hexagonal 
$\phi-\mathrm{Al}_{10} \mathrm{Cu}_{10} \mathrm{Fe}\left(\mathrm{Al}_{3} \mathrm{Ni}_{2}\right.$-type), whose $e / a$ values are all close to 1.86 . The last phase is a typical vacancy-ordered B2 superstructure (Dong 1995b). In the Al-Cu-Fe ternary phase diagram the $e / a$-constant line intercepts the Al-Cu binary system by the $\mathrm{Al}_{3} \mathrm{Cu}_{4}$ composition, where two new orthorhombic approximants $o \mathrm{~F}_{2}$ and $o \mathrm{I}_{1}$ were found.

The identification of the B2-based approximants is also important to practical applications. Quasicrystals have many superior properties but they are also extremely brittle, porous and composition-sensitive. It is therefore, interesting to substitute them by approximant materials, particularly B2-based ones, which are more easily prepared and which should have similar performances. Such a conjecture is confirmed by an investigation of the electronic structure of a series of $\mathrm{Al}-\mathrm{Cu}$ phases using soft X-ray emission and absorption spectroscopies (Fournee et al 1998). Some of these phases, like the icosahedral $\mathrm{Al}-\mathrm{Cu}-\mathrm{Fe}$ quasicrystal, are indeed characterized by nearly spherical Brillouin zones with a narrow but pseudo-gap.

The content followed is divided into two parts. In the first part, we will summarize structural relationships between the B2-based approximants and quasicrystals. We will discuss several B2-based approximants, namely B2, $\tau 2-\mathrm{CaF}_{2}, \tau 3-\mathrm{Al}_{3} \mathrm{Ni}_{2}, \gamma-\mathrm{Al}_{4} \mathrm{Cu}_{9}$ and $\varepsilon 2-\mathrm{Al}_{2} \mathrm{Cu}_{3}$, from the viewpoint of valence electron concentration and atomic structure correlation. Then we will report on an investigation of the friction behaviour of some samples containing the B2-type of phase but with different $e / a$ ratios in $\mathrm{Al}-\mathrm{Cu}-\mathrm{Fe}$ systems. The objective of this research is to find property proofs to support the valence electron criterion for approximants.

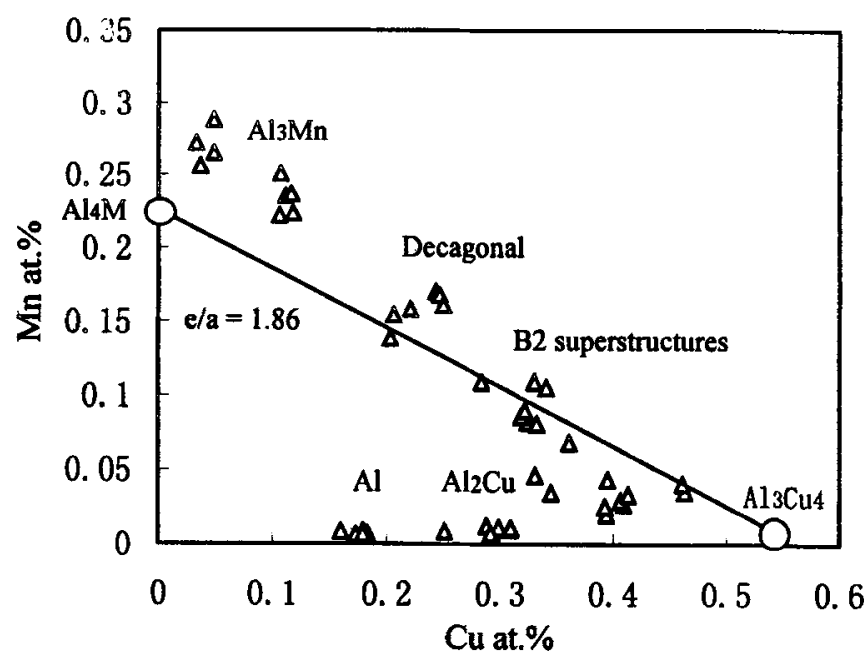

Figure 1. Al- $\mathrm{Cu}-\mathrm{Mn}$ composition diagram. The straight line represents an $e / a$-constant line with an $e / a$ ratio of 1.86 .

\section{Correlation between B2-based approximants and quasicrystals}

\subsection{B2-based approximants in the $A l-C u-M n$ system}

B2-based approximants constitute an important group of $e / a$-constant phases. In order to know the phase types, we have carried out a systematic investigation on the $\mathrm{Al}-\mathrm{Cu}-\mathrm{Mn}$ system. Figure 1 reports a composition chart at room temperature for $\mathrm{Al}-\mathrm{Cu}-\mathrm{Mn}$ system. The composition data were measured by EPMA on as-cast samples. To the left of the decagonal phase zone are located a group of B2 superstructures and to its right some complex approximants that are related to the $\mathrm{Al}_{3} \mathrm{Mn}$ structure. By using TEM, we have determined the orientation relationships among all these phases. Figure 2 gives selected area electron diffraction (SAED) patterns parallel to the 10 -fold axis of the decagonal phase. We see that the strong spots of the complex approximants superpose well those of the decagonal phase but most of the B2-based ones do not exhibit similar features, with the exception of a FCC phase with a large unit cell parameter $(a=1.756 \mathrm{~nm})$. Lists of the $e / a$-constant phases are reported in table 1 . We will see in the following sections that these phases share some common features with quasicrystals.

\subsection{Valence electron concentration correspondence}

The first criterion for an approximant is the valence electron concentration constancy (Dong 1995a). Such an information is provided in table 2 , where both $e / a$ (valence electron number per atom) and $N$ (valence electron number per unit volume in $\mathrm{nm}^{3}$ ) are calculated from composition and density data. We see that the $N$ values are very constant but $e / a$ may vary with densities. The constancy of the former values directly determines that the Fermi diameters $2 k_{\mathrm{F}}$ are also constant so that these phases are electron phases with their $2 k_{\mathrm{F}}$ being close to intense peaks.

\subsection{Atomic structure similarity}

The B2-based approximants have in general smaller unit cells than the complex approximants and their resemblance with quasicrystals is not as obvious. In the following, we discuss the structure features of $\mathrm{B} 2, \tau 2, \tau 3, \gamma-\mathrm{Al}_{4} \mathrm{Cu}_{9}$, and $\varepsilon 2-\mathrm{Al}_{2} \mathrm{Cu}_{3}$. For the $\mathrm{FCC}$ phase with $a=1.756 \mathrm{~nm}$, which is a superstructure of $\gamma$-brass, the reader is referred to the paper by Ge and Kuo (1998).

2.3a Local pentagonal atomic network in $\{110\}$ B2 planes: Although the B2 structure is simple, we can still identify local pentagonal atomic configurations by linking the atoms in a special way (Dong et al 1992). 
According to the SAED pattern in figure 2, the orientation relationship between $B 2$ and decagonal quasicrystal is the following: $\langle 110\rangle \mathrm{B} 2 / / 10-$ fold, $\langle 1-10\rangle \mathrm{B} 2 / / 2 \mathrm{P},\langle 001\rangle \mathrm{B} 2 / / 2 \mathrm{D}$ (figure $3 a$ ). We see in figure $3 b$ that atoms can be grouped into pentagons, though deformed, on the $\{110\}$ B2 plane. This means that 5 -fold or 10 -fold symmetries are hidden in the simple cubic structure.

Moreover, we have also found that $180^{\circ} /\langle 111\rangle$ is the chemical twinning mode of the B2 structure that is responsible for the formation of pentagonal atomic networks in $\mathrm{Al}-\mathrm{Cu}$ approximants. Successive application of this twinning will lead to 5-fold twinning of the B2 structure (figure 4).

2.3b Cuboctahedron in $\tau 2$ : This phase is the prototype of a series of vacancy-ordered ' $\tau$ ' phases, uncovered by Lu and Chang (1957) and studied in detail by Sande et al (1978). Their structures can be described in terms
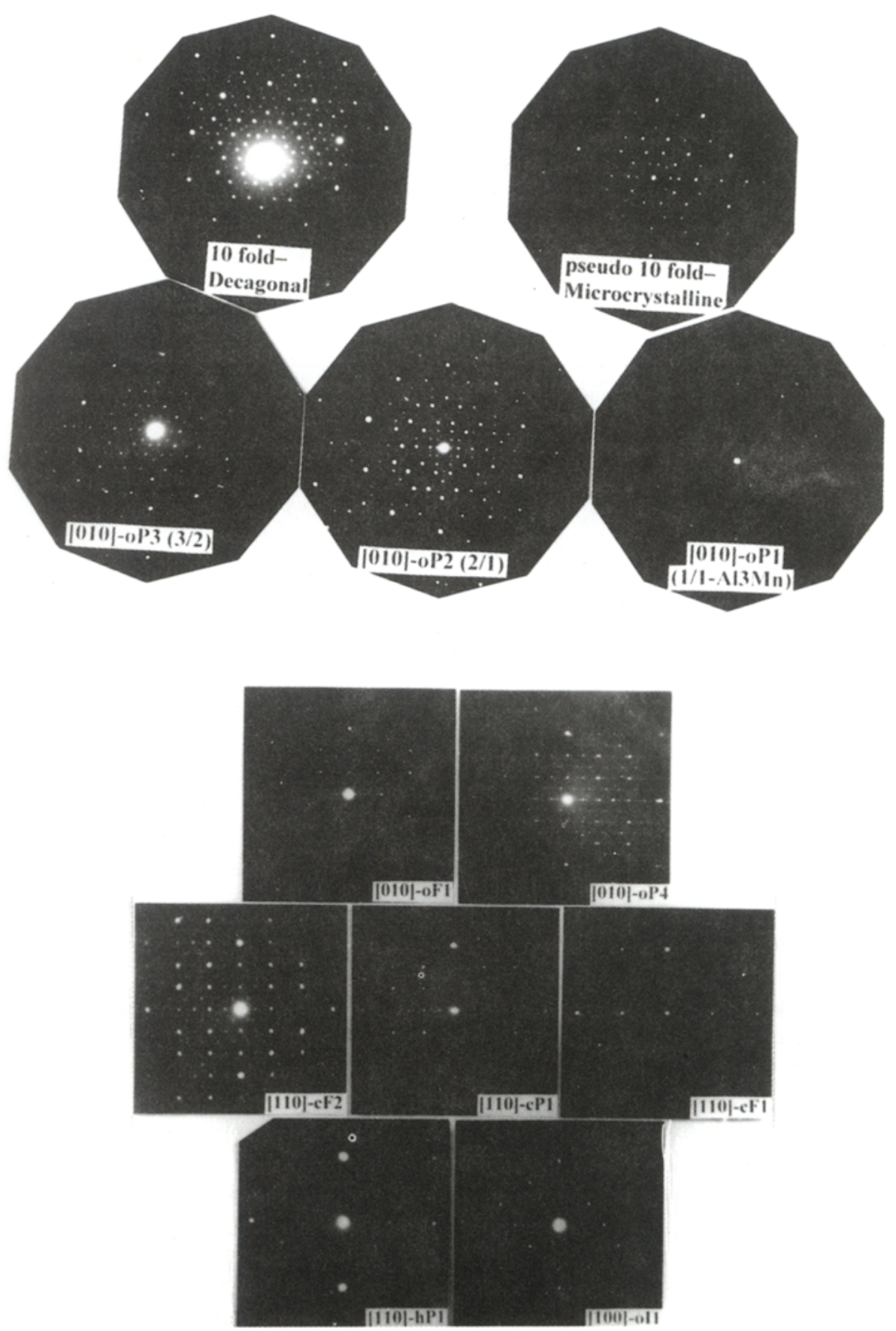

Figure 2. SAED patterns of approximants parallel to the 10 -fold axis of the decagonal phase in $\mathrm{Al}-\mathrm{Cu}-\mathrm{Mn}$ system. 
Table 1. The $e / a$-constant phases in Al-Cu-Mn system.

\begin{tabular}{|c|c|c|c|c|}
\hline \multicolumn{2}{|l|}{ Phase } & Structure (lattice parameters in $\mathrm{nm}$ ) & $\begin{array}{l}\text { Average } \\
\text { composition (at.\%) }\end{array}$ & $e / a$ \\
\hline \multicolumn{3}{|c|}{$\begin{array}{l}\text { Decagonal and microcrystalline } \\
\text { structures }\end{array}$} & $\mathrm{Al}_{61.8} \mathrm{Cu}_{24.0} \mathrm{Mn}_{14.2}$ & $1 \cdot 81$ \\
\hline $\begin{array}{l}\mathrm{Al}_{3} \mathrm{Mn} \text {-based } \\
\text { complex } \\
\text { approximants }\end{array}$ & $\begin{array}{l}o \mathrm{P}_{1}-\mathrm{Al}_{3}(\mathrm{Cu}, \mathrm{Mn}) \\
o \mathrm{P}_{2} \\
o \mathrm{P}_{3}\end{array}$ & $\begin{array}{l}(1 / 1,1 / 1) \text { type, } 1.259,1.242,1.479 \\
(2 / 1,2 / 1) \text { type, } 2.037 \approx \tau \times 1.259,1.242,2.393 \approx \tau \times 1.479 \\
(3 / 2,3 / 2) \text { type, } 3.296 \approx \tau^{2} \times 1.259,1.242,3.872 \approx \tau^{2} \times 1.479\end{array}$ & $\mathrm{Al}_{69.9} \mathrm{Cu}_{3 \cdot 5} \mathrm{Mn}_{26.6}$ & $1 \cdot 60$ \\
\hline \multirow[t]{4}{*}{$\begin{array}{l}\text { B2-based } \\
\text { approximants }\end{array}$} & $\begin{array}{l}o \mathrm{P}_{4} \\
o \mathrm{~F}_{1} \\
c \mathrm{~F}_{2}\end{array}$ & $\begin{array}{l}(1 / 1,3 / 2) \text { type, } 1.259,1.242,3.872 \approx \tau^{2} \times 1.4790 \\
(1 / 1,5 / 3) \text { type, } 1.259,1.242,6.265 \approx \tau^{3} \times 1.4790 \\
1.756\end{array}$ & & \\
\hline & $c \mathrm{P}_{1}$ & $\gamma-\mathrm{Al}_{4} \mathrm{Cu}_{9}$ type, 0.878 & $\mathrm{Al}_{46.39} \mathrm{Cu}_{49.53} \mathrm{Mn}_{4.08}$ & 1.81 \\
\hline & $c \mathrm{~F}_{1}$ & $\tau 2, \mathrm{CaF} 2$ type, 0.585 & $\mathrm{Al}_{55.9} \mathrm{Cu}_{33.4} \mathrm{Mn}_{10.7}$ & 1.80 \\
\hline & $\begin{array}{l}h \mathbf{P}_{1} \\
o \mathrm{I}_{1}\end{array}$ & $\begin{array}{l}\tau 3, \mathrm{Al}_{3} \mathrm{Ni}_{2} \text { type, } 0.414,0.507 \\
\mathrm{Al}_{2} \mathrm{Cu}_{3}, 0.408_{3}, 0.707_{4}, 0.999_{5}\end{array}$ & $\begin{array}{l}\mathrm{Al}_{55.9} \mathrm{Cu}_{33.4} \mathrm{Mn}_{10.7} \\
\mathrm{Al}_{41.3} \mathrm{Cu}_{58.7}\end{array}$ & $\begin{array}{l}1 \cdot 80 \\
1.83\end{array}$ \\
\hline
\end{tabular}

Table 2. Structural data and valence electron concentration information of the B2-based approximants in the Al-Cu-Mn system.

\begin{tabular}{|c|c|c|c|c|c|}
\hline Composition (at.\%) & $\begin{array}{l}\text { Number of } \\
\text { atoms per } \mathrm{nm}^{3}\end{array}$ & $\begin{array}{l}\text { Valence electron } \\
\text { number per atom } \\
(e / a)\end{array}$ & $\begin{array}{l}\text { Valence electron } \\
\text { number per } \mathrm{nm}^{3}(N)\end{array}$ & $\begin{array}{l}\text { Fermi diameter } \\
\qquad 2 k_{\mathrm{F}}\left(\mathrm{nm}^{-1}\right)\end{array}$ & $\begin{array}{l}\text { Intense peak } \\
k_{\text {intense }}\left(\mathrm{nm}^{-1}\right)\end{array}$ \\
\hline$\tau 2-\mathrm{Al}-\mathrm{Cu}-\mathrm{Mn}$ & 59.9 & 1.80 & $107 \cdot 7$ & $29 \cdot 4$ & $30 \cdot 4$ \\
\hline$\phi-\mathrm{Al}_{10} \mathrm{Cu}_{10} \mathrm{Fe}(\tau 3)$ & $67 \cdot 2$ & 1.81 & $121 \cdot 2$ & $30 \cdot 7$ & $30 \cdot 6,30 \cdot 3$ \\
\hline$\gamma-\mathrm{Al}_{4} \mathrm{Cu}_{9}$ & 78.8 & 1.62 & $127 \cdot 3$ & $31 \cdot 1$ & $30 \cdot 6$ \\
\hline$o \mathrm{~F}_{2}-\mathrm{Al}_{3} \mathrm{Cu}_{4}$ & $69 \cdot 3$ & 1.86 & 128.9 & $31 \cdot 3$ & $30 \cdot 8$ \\
\hline$o I_{1}-\mathrm{Al}_{2} \mathrm{Cu}_{3}$ & $69 \cdot 3$ & 1.80 & $124 \cdot 7$ & 30.9 & $30 \cdot 8$ \\
\hline$\varepsilon 2-\mathrm{Al}_{2} \mathrm{Cu}_{3}$ & $71 \cdot 6$ & 1.74 & $124 \cdot 7$ & $30 \cdot 9$ & $30 \cdot 4,30 \cdot 3$ \\
\hline$i-\mathrm{Al}_{62.3} \mathrm{Cu}_{24.9} \mathrm{Fe}_{12.8}$ & $66 \cdot 7$ & 1.86 & $124 \cdot 1$ & $30 \cdot 9$ & $31.4,29.9$ \\
\hline
\end{tabular}

of a basic B2-type of cell with ordering along the [111] direction. Chattopadhyay et al (1987) first noted the possible link between the vacancy-ordering and 1-dimensional quasi-periodicity. They pointed out that the vacancy layers in the $\tau$ phases follow a Fibonacci sequence. This phase is termed $\tau 2$ because the vacancy-ordering planes occur every 2 layers.

Its structure can either be described by a rhombohedral cell or FCC cell. In figure $5 a$ is drawn its atomic structure in one FCC cell that can be regarded as stacking eight B2 basic cells. All the FCC lattice sites are vacant so that the vacancy site concentration (with respect to the B2 structure) is $25 \%$. This is the highest among all vacancy-ordered phases. This structure is in fact the well-known $\mathrm{CaF}_{2}$ type.

Its orientation relationship with quasicrystals is the same as that of B2. Its basic atomic cluster forms a cuboctahedron with 12 vertices formed by intersection of three perpendicular squares with edge length of $a \sqrt{2}$. This polyhedron is transformed into an icosahedron when the squares are changed into rectangles with edge length ratio of $\tau: 1$ (figure $5 b$ ). Such a transformation is facilitated by the presence of vacancies in the FCC sites.

2.3c Vacancy-ordering in $\tau 3$ : This type of phase has a hexagonal structure with space group $P-3 \mathrm{ml}$ (Bradley and Taylor 1937). It is characterized by vacancy ordering in a B2 superlattice. One unit cell contains three B2 pseudocells, with a cell formula of $\mathrm{Al}_{3} \mathrm{Ni}_{2} \square_{1}, \square$ representing one vacancy site. The vacancy sites are ordered into hexagonal network on a $\{111\}$ plane of the B2 pseudocell with three-layer period, determining the diagonal of the rhombohedral cell or in the hexagonal coordination, the length of the axis c.

The $\mathrm{Al}_{3} \mathrm{Ni}_{2}$ structure, designated as $\tau 3$, has a vacancylayer period of three layers.

The following features have been noticed (Dong 1995b) (figure ${ }^{\circ}$ ): (i) the structure unit projected along the direction parallel to the 5 or 10 fold axis of quasicrystals 


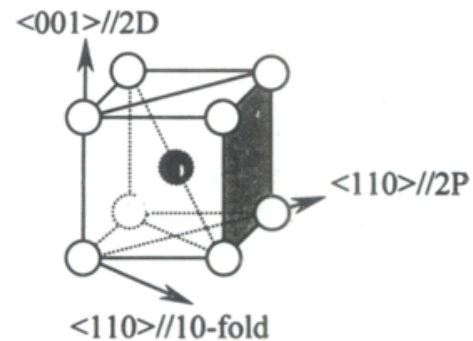

(a)

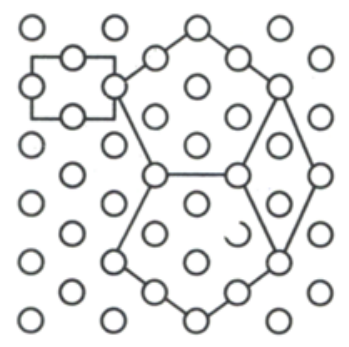

(h)

Figure 3. Orientation relationship between B2 and decagonal quasicrystal (a) and pentagonal atomic configurations in the $\langle 110\rangle_{\mathrm{B} 2}$ plane (b).

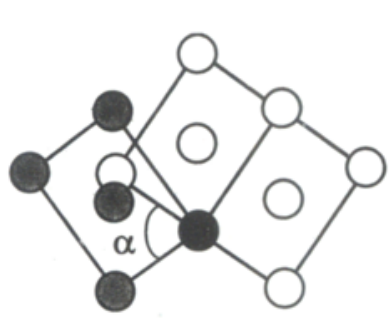

(a)

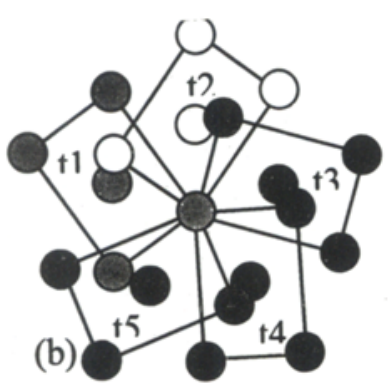

Figure 4. The $180^{\circ} /\langle 111\rangle_{\mathrm{B} 2}$ operation being equivalent to a rotational twinning $\alpha /\langle 011\rangle_{\mathrm{B} 2} \alpha \approx 70.53^{\circ}$ (a) and five-fold twinning of the $B 2$ structure resulting from successive application of the $180^{\circ} /(111\rangle_{\mathrm{B} 2}$ twinning (b). is orthorhombic containing $3 \times 3 \times 3 \mathrm{~B} 2$ cells with lattice parameters similar to that of the $\gamma-\mathrm{Al}_{4} \mathrm{Cu}_{9}$ projected along $a\langle 1-10\rangle$ direction. This means that these two phases are quite closely related to each other. In the next section we will see that the latter phase indeed contains a lot of quasicrystal information (ii) the $\mathrm{Al}_{3} \mathrm{Ni}_{2}$ phase is formed by stacking six (102) or $(-120)$ layers, while D-AlMn also has a six-layer stacking sequence along the 10-fold axis and (iii) the vacancy concentration of the $\mathrm{Al}_{3} \mathrm{Ni}_{2}$ structure is comparable to that of quasicrystals. On the flat and puckered layers of D-AlMn, such values are respectively $21 \%$ and $11 \%$. The average value is about $14 \%$. The $\mathrm{Al}_{3} \mathrm{Ni}_{2}$ structure has a slightly higher vacancy concentration of about $17 \%$.

$2.3 \mathrm{~d}$ Icosahedral chains in $\gamma-\mathrm{Al}_{4} \mathrm{Cu}$ : The atomic structure of the $\gamma-\mathrm{Al}_{4} \mathrm{Cu}_{9}$ phase was resolved by Bradley and Jones (1933), who noted its structural similarity with $\gamma$-brass. This structure can be described by clusters of 26 atoms located on a body centred cubic lattice. The large $\mathrm{Al}_{4} \mathrm{Cu}_{9}$ cell $(a=8.7068 \AA)$ contains 27 B2-type pseudocells with two vacant sites. Its crystallographic orientation relationship with quasicrystals is the same as that of the B2-type structure. Its crystallographic relationship with quasicrystals has been analyzed in a recent paper (Dong 1996). Three striking similarities with the decagonal $\mathrm{Al}-\mathrm{Mn}$ quasicrystal have been revealed:

(I) Along the $\langle 1-10\rangle$ direction, which corresponds to the 5(10)-fold direction of quasicrystals, are stacked only two kinds of $\{110\}$ atomic layers, flat layer and puckered layer, as in the case of the decagonal quasicrystalline structure. Both the stacking sequence and the periodicity
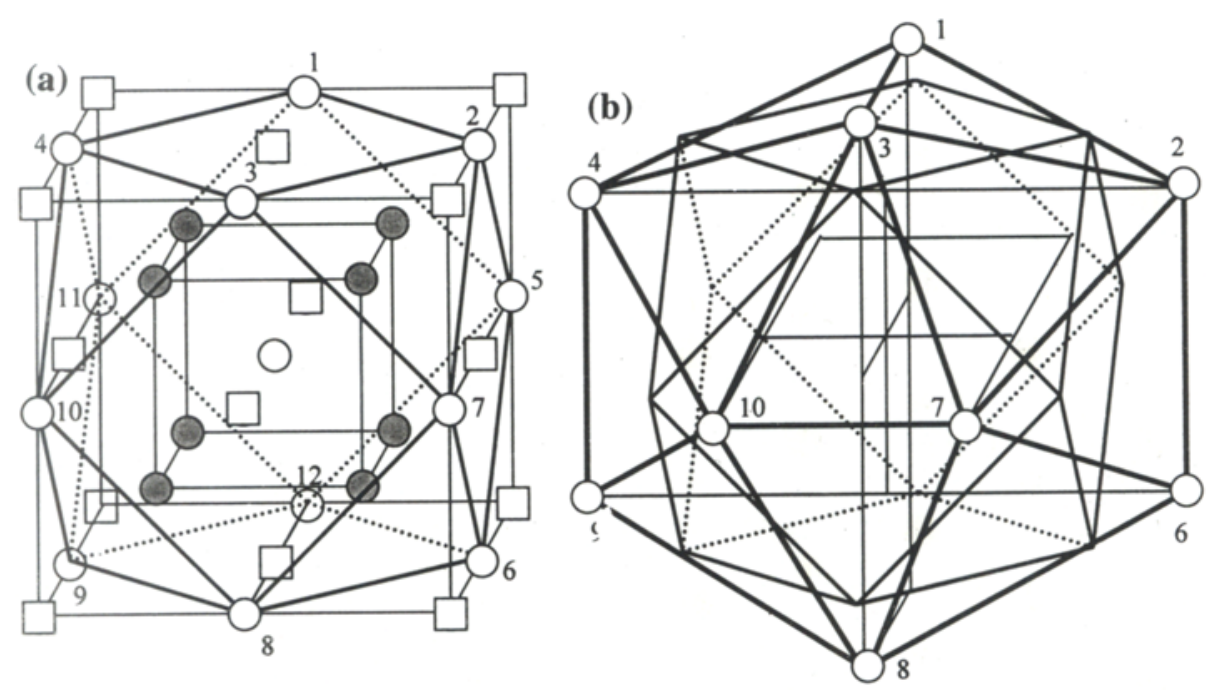

Figure 5. Cuboctahedron in FCC- $\tau 2$-structure (a) and its relationship with icosahedron. (b) The 12 vertices in the cuboctahedron and icosahedron are numbered in order to show the correspondence. 
along this direction resemble those of the Al-Mn decagonal quasicrystal and its close approximants.

(II) On the $\{1-10\}$ atomic planes, there are two kinds of elongated hexagonal subunits consisting of one convex pentagon and one concave pentagon. Around each vacancy site is formed a small convex pentagon located inside the larger convex pentagon (figure 7).

(III) These small pentagons are aligned along the $\langle 1-10\rangle$ direction, forming pentagonal chains, so that its structure can also be viewed as parallel packing of pentagonal columns.

2.3e Pentagonal atomic network in $\varepsilon_{2}-\mathrm{Al}_{2} \mathrm{Cu}_{3}$ phase: In an $\mathrm{Al}_{3} \mathrm{Cu}_{4}$ sample, whose $e / a$ is the same as that of the icosahedral $\mathrm{Al}-\mathrm{Cu}-\mathrm{Fe}$ quasicrystal, we have observed two new phases: face-centred orthorhombic $o F_{2}$ $\mathrm{Al}_{43.2} \mathrm{Cu}_{56.8} \quad\left(a=0.816_{6}, \quad b=1.414_{9}, \quad c=0.999_{5} \mathrm{~nm}\right)$ and body-centred orthorhombic $o \mathrm{I}_{1}-\mathrm{Al}_{41.3} \mathrm{Cu}_{58.7} \quad\left(a=0.408_{3}\right.$, $b=0.707_{4}, c=0.999_{5} \mathrm{~nm}$ ). Their twinning modes may be explained by a solid phase transition from their hightemperature parent phase $\varepsilon 2-\mathrm{Al}_{2} \mathrm{Cu}_{3}$. The $\varepsilon 2-\mathrm{Al}_{2} \mathrm{Cu}_{3}$ phase is hexagonal with parameters $a=0.4146 \mathrm{~nm}$, $c=0.5063 \mathrm{~nm}$ (El-boragy et al 1972). Its space group is $P 6_{3} / m m c$. It is a $\mathrm{B} 2$ superstructure with a partially occupied NiAs structural type.

The orientation relationships of $\varepsilon 2$ with respect to $o \mathrm{~F}$ and oI are $c_{c 2} / / c_{o \mathrm{~F}} / / c_{o \mathrm{P}}, \quad[110]_{\varepsilon 2} / / a_{o \mathrm{~F}} / 2 / / a_{o \mathrm{I}}, \quad[1-10]_{\varepsilon 2} / / b_{o \mathrm{~F}} / 2 / /$ $b_{o r}$. These relationships are shown in figures 8(a) and (b), where $o \mathrm{I}$ and $o \mathrm{~F}$ cells are marked on two successive $(110)_{\varepsilon 2}$ layers of $\varepsilon 2$. This plane is parallel to a $\{110\}_{\mathrm{B} 2}$ of the basic B2 lattice. This plane is also perpendicular

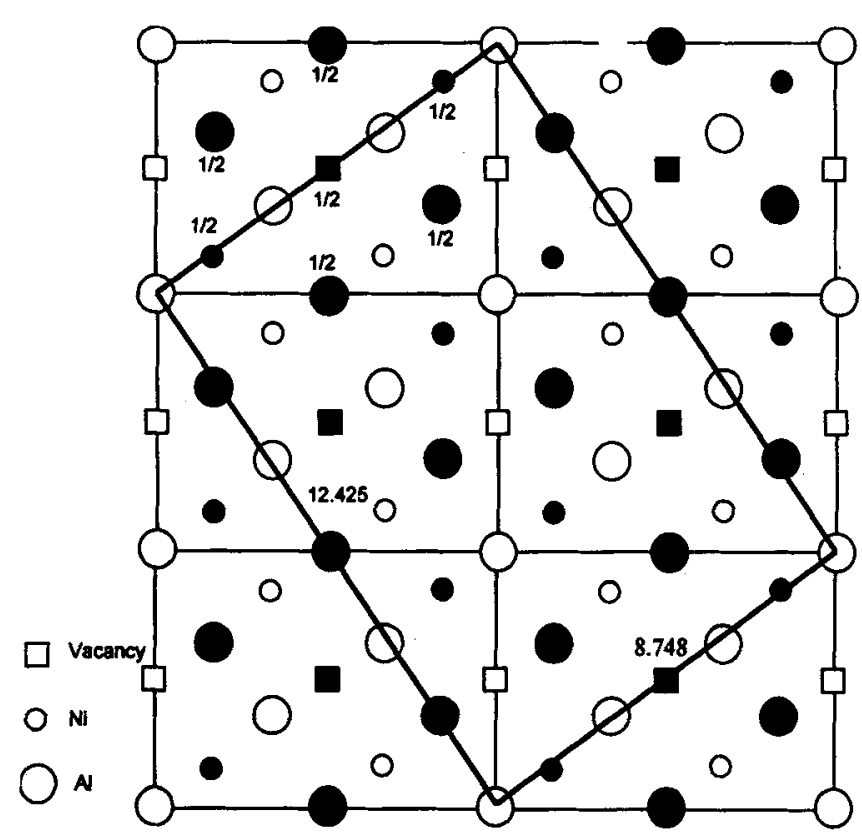

Figure 6. The $\mathrm{Al}_{3} \mathrm{Ni}_{2}$ structure projected along [010] showing a pseudo orthorhombic cell containing $3 \times 3 \times 3$ basic $\mathrm{B} 2$ cells. to the 5- or 10-fold axis of quasicrystals. A distinct feature of approximants is noted; deformed pentagons in these planes form a network that resembles the local atomic configurations in the 5 -fold or 10 -fold planes of quasicrystals.

\section{Friction coefficients of the B2-type of phases with different $e / a$ ratios in the Al-Cu-Fe system}

Quasicrystalline specimens exhibit low friction coefficients (Dubois et al 1991). Approximants should have similar properties as quasicrystals do. Although we have pointed out that the B2 superstructures can be approximants of quasicrystals according to the wellestablished $e / a$-constant criterion, there is still little proof to support property similarity between these B2 superstructures and quasicrystals. Particularly, for the simplest B2 structure, ambiguity may arise in identifying the B2-type approximant in a given alloy system where the B2 structure may exist over a wide composition zone. Therefore, we have carried out a study on the friction behaviours of the B2 structure with different $e / a$ ratios in $\mathrm{Al}-\mathrm{Cu}-\mathrm{Fe}$ system. The following samples have been chosen: an annealed ingot with $\mathrm{Al}_{62.5} \mathrm{Cu}_{25} \mathrm{Fe}_{12.5}$ composition containing mostly the icosahedral quasicrystalline phase $\left(760^{\circ} \mathrm{C}\right.$ for $\left.10 \mathrm{~h}\right)$; an as-cast ingot with compositions $\mathrm{Al}_{7} \mathrm{Cu}_{2} \mathrm{Fe}(e / a=2 \cdot 1)$ which contains a nonapproximant $\omega$ - $\mathrm{Al}_{7} \mathrm{Cu}_{2} \mathrm{Fe}$; as-cast ingot $\mathrm{Al}_{50} \mathrm{Cu}_{40} \mathrm{Fe}_{10}(e / a=1 \cdot 7)$ containing a B2-type phase, an annealed ingot with $\mathrm{Al}_{52.5} \mathrm{Cu}_{37.5} \mathrm{Fe}_{10}$ composition $(e / a=1.75)$ containing a B2type phase $\left(600^{\circ} \mathrm{C}\right.$ for $\left.5 \mathrm{~h}\right)$; two powder-sintered samples with nominal composition $\mathrm{Al}_{62.5} \mathrm{Cu}_{25} \mathrm{Fe}_{12.5}$ containing only the B2-type of phases, prepared respectively by hot pressing (40 MPa at $800^{\circ} \mathrm{C}$ for $15 \mathrm{~min}$ ) and cold pressing
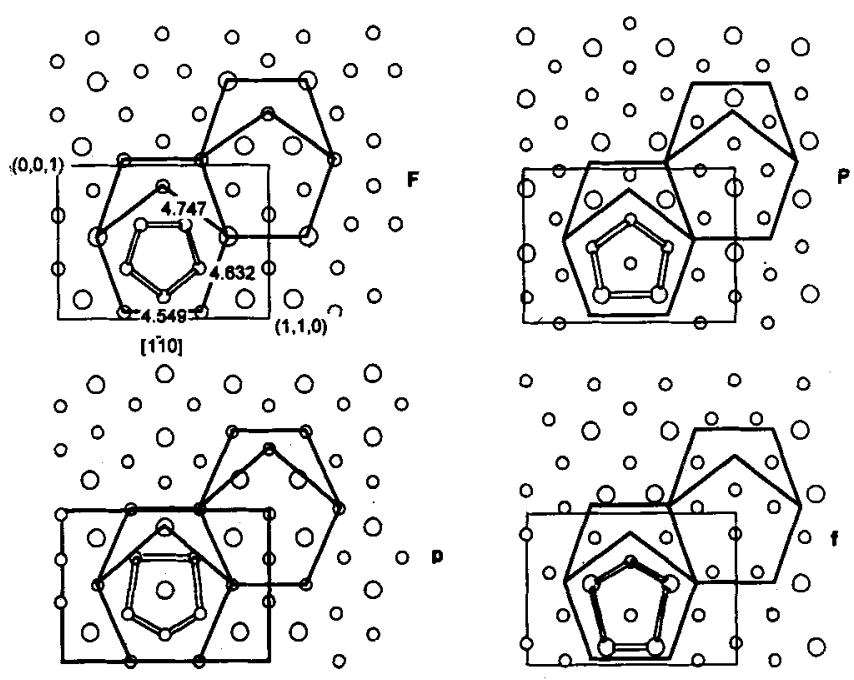

Figure 7. Pentagons and elongated hexagons on a $\{1-10\}$ plane of the $\mathrm{Al}_{4} \mathrm{Cu}_{9}$ phase. Labels $\mathrm{F}$ (f) and $\mathrm{P}$ (p) represent respectively, flat and puckered layers. 


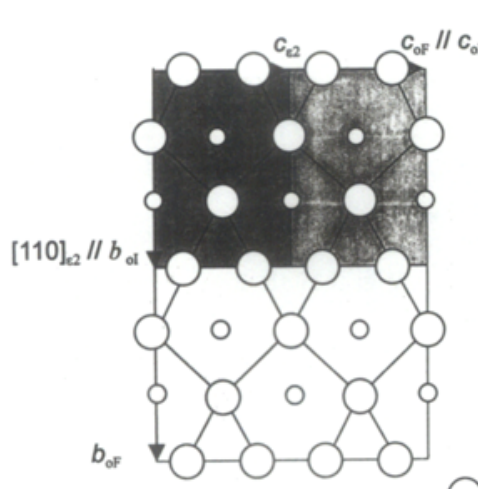

(a)

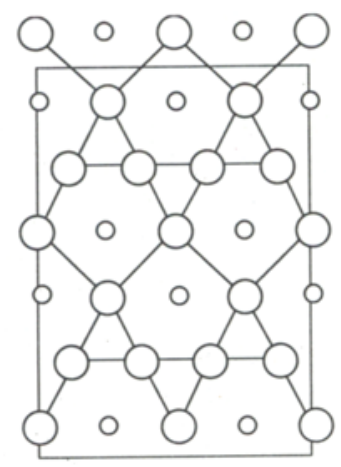

(b)

O Al

Figure 8. Structural relationships between $\varepsilon 2, o \mathrm{~F}$ and $o \mathbf{l}$. Two successive $\varepsilon 2-(110)$ layers are shown in (a) and (b), where unit cells of the three phases and their parallel relationships are marked.

Table 3. Friction coefficients of B2-type of phases with different $e / a$ ratios in comparison with a quasicrystalline sample and a low carbon steel.

\begin{tabular}{lcc}
\hline & $\begin{array}{c}\text { Valence } \\
\text { electron } \\
\text { number per } \\
\text { atom (e/a) }\end{array}$ & $\begin{array}{c}\text { Friction } \\
\text { coefficients }\end{array}$ \\
\hline Annealed IQC-AL ${ }_{62.5} \mathrm{Cu}_{25} \mathrm{Fe}_{12.5}$ & 1.86 & 0.12 \\
Cold-pressed $\mathrm{B} 2-\mathrm{Al}_{62.2} \mathrm{Cu}_{24.2} \mathrm{Fe}_{15.6}$ & 1.80 & 0.13 \\
Hot-pressed $\mathrm{B} 2-\mathrm{Al}_{64.5} \mathrm{Cu}_{21.2} \mathrm{Fe}_{14.3}$ & 1.86 & 0.14 \\
Annealed $\mathrm{B} 2-\mathrm{Al}_{52.5} \mathrm{Cu}_{37.5} \mathrm{Fe}_{10}$ & 1.75 & 0.19 \\
As-cast B2- $\mathrm{Al}_{50} \mathrm{Cu}_{40} \mathrm{Fe}_{10}$ & 1.70 & 0.23 \\
As-cast $\omega-\mathrm{Al}_{7} \mathrm{Cu}_{2} \mathrm{Fe}_{1}$ & 2.08 & 0.35 \\
Low carbon steel & & 0.40 \\
\hline
\end{tabular}

(compressed at $320 \mathrm{MPa})$ plus sintering $\left(800^{\circ} \mathrm{C}\right.$ for $5 \mathrm{~h}$ ); and a commercial low-carbon steel (carbon content in wt\% is less than $0.2 \%$ ) as a comparison.

Tribological tests were performed on a pin-on-disc-type machine, which allows to run pins of the materials to be tested against stationary steel rings (diameter $30 \mathrm{~mm}$, HRC 42-45).

The friction coefficient data obtained under $1 \mathrm{MPa}$ contact pressures at a sliding speed of $60 \mathrm{~mm} / \mathrm{sec}$ of the above samples were shown in table 2 . The friction coefficients of the sintered B2 samples with $e / a=1.86$ and the annealed quasicrystal are the lowest and only about one third of that of the low carbon steel at the same experimental condition. The samples containing the B2-type of phase but having e/a ratios different from 1.86 show higher friction coefficients than those B2 samples with $e / a=1 \cdot 86$. The non-approximant $\mathrm{Al}_{7} \mathrm{Cu}_{2} \mathrm{Fe}$ phase exhibits relatively high friction coefficient. Figure 9 illustrates the measured friction coefficients as a function

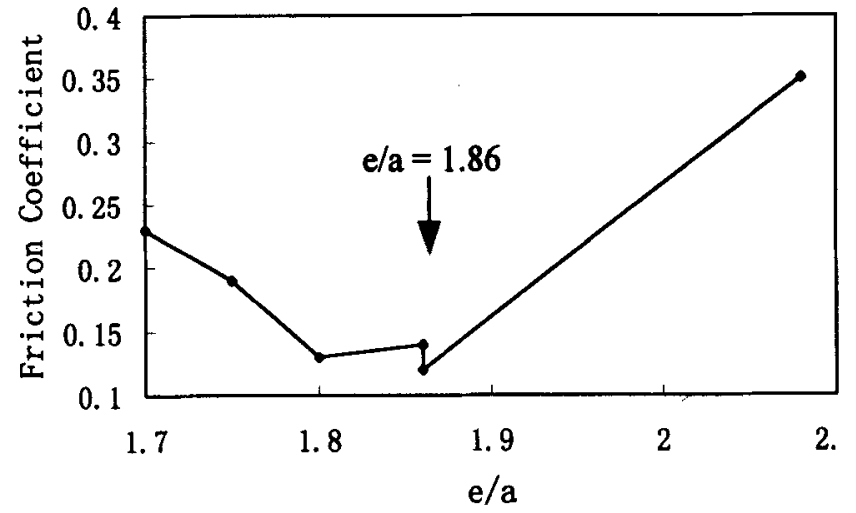

Figure 9. Measured friction coefficients as a function of $e / a$ ratios for some $\mathrm{AlCuFe}$ samples containing the $\mathrm{B} 2$ structure but having different $e / a$ ratios. The data are reported in table 2 .

of $e / a$ ratios. It is obvious that the friction coefficient increases when the $e / a$ ratios of the samples depart from 1.86 , the value of the AlCuFe icosahedral quasicrystal. This result indicates that the B2-type of phases can be regarded as an approximant only when its valence electron concentration is close to that of the quasicrystal. In other words, structure type alone cannot be a sufficient condition to define an approximant. The electronic structural correspondence should also be taken into account.

\section{Conclusions}

We have demonstrated that the $\mathrm{B} 2$ superstructures, with their valence electron concentrations being near those of their corresponding quasicrystals, should be regarded as approximants. Their atomic structures contain information of quasicrystals. A preliminary tribological investigation of the $\mathrm{B} 2$ structures with different $e / a$ ratios in $\mathrm{Al}-\mathrm{Cu}-\mathrm{Fe}$ system reveals that those $\mathrm{B} 2$ samples with $e / a$ ratios near that of the $\mathrm{AlCuFe}$ quasicrystal have low friction coefficients. Such a result indicates that such B2-type phases are approximants, which is in full support of the valence electron criterion for approximants.

\section{Acknowledgements}

The present work is supported by the National Natural Science Foundation of China under the grant No. 59525103. This work has also benefited from a grant by the French-Chinese Advanced Research Program on Materials (PRA MX 96/02).

\section{References}

Andersson S and Hyde B G 1974 J. Solid State Chem. 992 Beeli C and Horiuchi S 1994 Philos Mag. B70 215

Bradley A J and Jones P 1933 J. Inst. Metals 51131 
Bradley A J and Taylor A 1937 Philos. Mag. 231049

Chattopadhyay K, Lele S, Thangaraj N and Ranganathan S 1987 Acta Metall. 35727

Chien C L and Lu M 1992 Phys. Rev. B45 12793

Dong C 1995a Scr. Metall. et Mater. 33239

Dong C 1995b J. Phys. (Paris) 51625

Dong C 1996 Philos. Mag. A73 1519

Dong C, Dubois J M, Kang S S and Audier M 1992 Philos. Mag. B65 107

Dubois J M, Kang S S and Stebut J Von 1991 J. Mater. Sci. Lett. 10537

Dubois J M 1993 Phys. Scr. 4917
El-boragy M, Szepen R and Schubert K 1972 J. Less-Common Metals 29133

Fournee V, Belin E and Dubois J M 1998 J. Phys.: Condens. Matter 104231

Ge S P and Kuo K H 1998 J. Mater. Res. (submitted)

Jenks C J et al 1997 Proc. of the int. conf. on aperiodic crystals, Alpe d'Huez, France (Singapore: Scientific)

Lu S S and Chang T 1957 Acta Phys. Sinica 13150

Sande M Van, Ridder R De, Landuyt $\mathrm{J}$ Van and Amelinckx $S$ 1978 Phys. Status Solidi A50 587

Zhang Z, Feng Y C, Williams D B and Kuo K H 1993 Philos. Mag. B67 237 